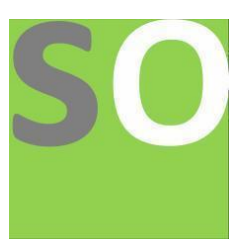

Article title: The Impact of Gender on Adjustment Level of Dire Dawa University Lecturers

Authors: Mustefa Jibril[1]

Affiliations: Dire Dawa University, Dire Dawa, Ethiopia[1]

Orcid ids: 0000-0002-3165-2410[1]

Contact e-mail: mustefazinet1981@gmail.com

License information: This work has been published open access under Creative Commons Attribution License $\mathrm{http}: / / c r e a t i v e c o m m o n s . o r g / l i c e n s e s / b y / 4.0 /$, which permits unrestricted use, distribution, and reproduction in any medium, provided the original work is properly cited. Conditions, terms of use and publishing policy can be found at https://www.scienceopen.com/.

Preprint statement: This article is a preprint and has not been peer-reviewed, under consideration and submitted to ScienceOpen Preprints for open peer review.

DOI: 10.14293/S2199-1006.1.SOR-.PPKRXDR.v1

Preprint first posted online: 16 July 2021

Keywords: Adjustment, Dire Dawa, Teachers Adjustment Inventory, Overload course, Lecturers 


\title{
The Impact of Gender on Adjustment Level of Dire Dawa University Lecturers
}

\author{
Mustefa JIBRIL \\ School of Electrical \& Computer Engineering, Dire Dawa Institute of Technology, Dire Dawa, \\ Ethiopia \\ mustefa.jibril@ddu.edu.et
}

\begin{abstract}
The present investigation is to find out the Adjustment of Dire Dawa University Lecturers concerning their gender. The sample consisted of 120 lecturers out of which 60 were male and 60 were female. For this purpose of investigation, the Teachers Adjustment Inventory was used. The obtained data were analyzed through the "t" test to know the mean difference between the lecturers concerning their gender. The result shows that there is no significant difference in University, Teaching, and Overload course adjustment of male and female Dire Dawa university Lecturers. But there is a significant difference in conducting research adjustment of male \& female Lecturers at 0.05 levels. It means males Conducting research adjustment are better than female Lecturers.
\end{abstract}

Keywords: Adjustment, Dire Dawa, Teachers Adjustment Inventory, Overload course, Lecturers

\section{Introduction}

The term of service is often used as a synonym for accommodation and adaptation. Strictly speaking, this means that the assessment results are likely to be affected by any of these processes. It is used to highlight the fact that the group in the battle for survival is in the public life as well as at the physical level. In the process of adjustment, which are the most important factors in the individual and the environment. In personality research, taking into account the genetic and biological factors, psychological factors, and quality of a person's socialization. Whereas, the area contains all of the social factors. Every person, from the moment he or she leaves the family and goes to school, helps to be in a long series of changes across their entire personality, and the environment.

The term "adjustment" refers to the degree to which a person has the personality that acts effectively in the human world. With the help of the students to adapt to the changes in the environment, it is one of the main goals of the education system. The device can be thought of as a process and as a result of this process, in the form of several projects. The adjustment is a continuous process. It begins at birth and continues without interruption until the end of life. The individual and his or her environment are constantly changing, as are the needs, following the requirements of the ever-changing business environment. In this regard, it can be expected that, in the process, or with the terms of the modification of an individual will vary from situation to situation. Adaptation as a process is of great interest to psychologists, teachers, and parents. To analyze this process, we have to include the study of the development of the individual, the length of the birth onward.

The modification of the relationship that is being established between instagram and the environment. Each group is in a particular position in a social situation. In psychology, the result is interpreted as a behavioral process of balancing conflicting needs, or needs against obstacles in 
the environment. Modification refers to a situation in which a person feels that their needs are, or will be, complied with and that their behavior is consistent with that of their society and culture. The unit is a necessary quality to be able to live in peace in this world. The problem of the alignment begins at birth and continues until death, and a variety of situations appear in the house. Schools, colleges, and jobs and we have to put our needs and to accept what it is. The modification is in the process of achieving a balance between the needs of the body, and their satisfaction.

Therefore, in the light of the above facts, it can be said that as long as it is necessary for the performance of a study on the gender of the influence of the degree of adaptation of the staff. The researcher believes that the proposed study will be able to fill this gap in the field of research.

\section{The objective of the study:}

The main objectives of the study were as under The purpose of the present study is the difference related to the university, teaching, conducting research, and overload course adjustment of Dire Dawa university lecturers concerning their gender.

\section{Hypothesis:}

1. There is no significant difference between university adjustments of Dire Dawa university lecturers concerning their gender.

2. There is no significant difference between teaching adjustments of Dire Dawa university lecturers concerning their gender.

3. There is no significant difference between conducting research adjustments of Dire Dawa university lecturers concerning their gender.

4. There is no significant difference between overload course adjustments of Dire Dawa university lecturers concerning their gender.

\section{Material and Methods}

Sample: The present study was carried out on lecturers of Dire Dawa University, Ethiopia. Elements of the study are 120 lecturers out of which 60 were male and 60 were female.

Research Design: For the research work, the research design was to meet the objectives, the ex-post-facto design will be used or the data will be analyzed and proper statistical techniques will be used.

Tool: Teachers Adjustment Inventory (TAI) was used. The adjustment inventory consists of 60 items with a yes/ impartial /no response pattern. 15 were a university, 15 were Teaching, 15 Conducting research \& 15 were Overload course Adjustment Items. The reliability factor is Split Half 0.88 and test-retest $0.69 \&$ Validity is 0.70.

\section{Result and Discussions}

The main objective of the present study was to do a study of the Adjustment of Dire Dawa university lecturers male and female. The statistical analysis of the research study, the data will be statistically analyzed by following standard statistical methods. An Independent t-test will be applied to test the hypothesis. Results discussions of the present study are as under:

Table No: 1, Showing the Mean, SD, and " $t$ " value of university adjustment of Dire Dawa Lecturers

\begin{tabular}{|l|l|l|l|l|l|l|l|}
\hline Variables & $\mathrm{N}$ & $\mathrm{M}$ & $\mathrm{SD}$ & $\begin{array}{l}\text { Mean } \\
\text { Diff. }\end{array}$ & $\mathrm{SE}_{\mathrm{D}}$ & ' $\mathrm{t}$ ' & Level of Sig. \\
\hline Male & 60 & 11.03 & 2.47 & 0.08 & 0.43 & 0.195 & Not Significant \\
\hline
\end{tabular}




\begin{tabular}{|l|l|l|l|l|l|l|l|}
\hline Female & 60 & 10.95 & 2.20 & & & & \\
\hline
\end{tabular}

$\mathrm{df}=118$

Table No: 2, Showing the Mean, SD, and "t" value of teaching adjustment of Dire Dawa Lecturers

\begin{tabular}{|l|l|l|l|l|l|l|l|}
\hline Variables & $\mathrm{N}$ & $\mathrm{M}$ & $\mathrm{SD}$ & $\begin{array}{l}\text { Mean } \\
\text { Diff. }\end{array}$ & $\mathrm{SE}_{\mathrm{D}}$ & ' $\mathrm{t}$ ' & Level of Sig. \\
\hline Male & 60 & 10.03 & 2.56 & 0.15 & 0.48 & 0.311 & Not Significant \\
\hline Female & 60 & 10.18 & 2.73 & 0.15 &
\end{tabular}

$\mathrm{df}=118$

Table No: 3, Showing the Mean, SD, and "t" value of conducting research adjustment of Dire Dawa Lecturers

\begin{tabular}{|l|l|l|l|l|l|l|l|}
\hline Variables & $\mathrm{N}$ & $\mathrm{M}$ & $\mathrm{SD}$ & Mean Diff. & $\mathrm{SE}_{\mathrm{D}}$ & ' $\mathrm{t}$ ' & Level of Sig. \\
\cline { 1 - 4 } & 60 & 11.75 & 2.10 & \multirow{2}{*}{0.82} & 0.39 & 2.11 & Significant at 0.05 level \\
\hline Female & 60 & 10.93 & 2.14 & & & & \\
\hline
\end{tabular}

Table No: 4, Showing the Mean, SD, and "t" value of Overload course adjustment of Dire Dawa Lecturers

\begin{tabular}{|l|l|l|l|l|l|l|l|}
\hline Variables & $\mathrm{N}$ & $\mathrm{M}$ & $\mathrm{SD}$ & $\begin{array}{l}\text { Mean } \\
\text { Diff. }\end{array}$ & $\mathrm{SE}_{\mathrm{D}}$ & 't' & Level of Sig. \\
\hline Male & 60 & 9.60 & 2.58 & 0.61 & 0.43 & 1.42 & Not Significant \\
\hline Female & 60 & 8.98 & 2.16 & 0.61 &
\end{tabular}

$\mathrm{df}=118$

\section{Discussions}

In the above result table No. 1 we can see that t-test was used to know the level of university adjustment of the lecturers. Where male means was $11.03 \&$ SD was 2.47 and female mean was $10.95 \&$ SD was 2.20 and difference between their ,te values was 0.195 it was not significant at 0.05 level. The result shows that there is no significant mean difference in university Adjustment between male and female lecturers. Thus, null hypothesis- I which states "there is no significant difference in the university adjustment level of Dire Dawa university lecturers concerning their university adjustment" is accepted.

In the above result table No.2, we can see that t-test was used to know the level of teaching adjustment of the lecturers. Where males mean was $10.03 \&$ SD was 2.56 and females mean was $10.18 \&$ SD was 2.73 and difference between their " $t$ " values was 0.311 it was not significant at 0.05 levels. The result shows that there is no significant mean difference in teaching adjustment between male and female lecturers. Thus the null hypothesis-II which states "there is no significant difference in the teaching adjustment level of Dire Dawa university lecturers concerning their teaching adjustment" is accepted.

In the above result table No.3, we can see that the " $t$ " test was used to know the level of conducting research adjustment of the lecturers. Where males mean was $11.75 \&$ SD was 2.10 and females mean was 10.93 \& SD was 2.14 and difference between their , te values was 2.11 it was significant at 0.05 level. Thus the null hypothesis-III states "there is no significant difference in the conducting research adjustment level of the lecturers concerning their conducting research 
adjustment". Here null hypothesis was rejected and the result shows that the conducting research adjustment is high of males than the females.

In the above result table No.4, we can see that t-test was used to know the level of Overload course Adjustment of the lecturers. Where males mean was 9.60 \& SD was 2.58 and females mean was 8.98 \& SD was 2.16 and difference between their " $t$ " values was 1.42 it was not significant at 0.05 level. The result shows that there is no significant mean difference in the Overload course adjustment of the male and female lecturers. Thus the null hypothesis-IV which states "there is no significant difference in the Overload course adjustment level of lecturers concerning their Overload course adjustment" is accepted.

\section{Conclusion}

The observation in the present study showed that there is no significant mean difference in university adjustment of the university lecturers concerning their gender. There is no significant mean difference in teaching adjustment of the university lecturers concerning their gender. There is a significant mean difference in conducting research adjustment of the university lecturers concerning their gender. Male lecturers' adjustment is more than females. There is no significant mean difference in overload course adjustment of the university lecturers concerning their gender.

\section{References}

[1]. Bhat, S. A., \& Beri, A. (2016). Social adjustment and job performance of college teachers: An analytical study. Indian Journal of Positive Psychology, 7(2), 206.

[2].Duchesne, S., Ratelle, C. F., Larose, S., \& Guay, F. (2007). Adjustment trajectories in college science programs: Perceptions of qualities of parents' and college teachers' relationships. Journal of Counseling Psychology, 54(1), 62.

[3]. Tariq, S., \& Adil, A. (2020). Rigidity as the mediator between temperaments and social adjustment: A comparative study of teachers of madaris and schools of Pakistan. Archive for the Psychology of Religion, 42(2), 194-210.

[4].Gray, R., Vitak, J., Easton, E. W., \& Ellison, N. B. (2013). Examining social adjustment to college in the age of social media: Factors influencing successful transitions and persistence. Computers \& Education, 67, 193-207.

[5].Dan, L. Y. W. Z. (2010). The Social Adjustment and Teachers' Self-adjustment to Their Role Expectations of Education-related Communities [J]. Teacher Education Research, 2.

[6]. Mistra, S. G. (2015). Study of Relationship between Emotional Intelligence and Social Adjustment. Third 21st CAF.

[7]. Bhat, S. (2014). Influence of organizational climate and social adjustment on job performance of teaching and non-teaching professionals. Education and Development, $3(1), 420-424$.

[8].Çevik - Durmaz, Y., Yalçinkaya - Önder, E., \& Timur, S. (2020). Preservice teachers' nomophobia levels, sense of loneliness, and adjustment to college life. Perspectives in Psychiatric Care.

[9].Nadeem, N. A., \& Bhat, G. A. (2014). A Study of Adjustment Level among Secondary School Teachers in Kashmir. Journal of Education and Practice, 5(10), 144-148. 